\title{
The Influence of Perceived Belonging on Massively Multiplayer Online Role-Playing Games
}

\author{
Claus-Peter H. Ernst \\ Frankfurt University of Applied Sciences \\ cernst@fb3.fra-uas.de
}

\begin{abstract}
While some service providers of Massively Multiplayer Online Role-Playing Games (MMORPGs) lose significant numbers of players over time, others maintain a strong growth trajectory. Drawing from the Uses and Gratifications Theory and the Need to Belong theory, we believe that an individual's Perceived Belonging (i.e., the degree to which a person feels connected to and accepted by others) positively influences his/her Actual MMORPG Usage, i.e., how often he/she plays MMORPGs. After collecting 71 online questionnaires and applying a structural equation modeling approach, we found that Perceived Belonging's positive influence on Actual MMORPG Usage is fully mediated by Perceived Enjoyment. Overall, our study suggests that MMORPG service providers should include belonging-oriented aspects into their games, such as the possibility of interacting and cooperating with other players, in order to increase individuals, game usage through their Perceived Belonging.
\end{abstract}

\section{Introduction}

Massively Multiplayer Online Role-Playing Games (MMORPGs) "are multiplayer role-playing games (RPGs) played online over the internet in a persistent world with hundreds, or even thousands of people simultaneously connected to the same server" [1, p. 1]. While some games still retain strong user growth, others struggle. For example, long-time industry leader World of Warcraft lost around $55 \%$ of its active players between 2010-2015 [37], which directly impacted their revenue since they have a subscription-based revenue model where players pay a monthly fee in order to play. As a result, MMORPG service providers have a strong interest in knowing the factors that drive actual usage.

To master the game in MMORPGs, players usually have to interact with other players for example via chats, by trading or by collaboratively completing quests $[1,11]$. Hence, in contrast to traditional role-playing games such as Final Fantasy
$V I I$, which are played offline and alone, there is a large social aspect embedded into most MMORPGs. The Need to Belong theory suggests that every person has, to differing extents, a fundamental need to connect with others and be accepted by them [e.g., 5] and the Uses and Gratifications Theory (U\&G) postulates that individuals' repeated usage of media is determined by their needs and wants, which are directly linked to their ultimate goal of gratification [33]. Drawing from these two theories, we believe that Perceived Belonging, that is, the degree to which a person feels connected to and accepted by other individuals $[5,16,27,35,41]$, is an important positive influence factor of MMORPG usage and we seek to examine whether this influence is a direct influence on MMORPG usage, an indirect influence on MMORPG usage through Perceived Enjoyment, or both.

After surveying 71 German-speaking Internet users and applying a structural equation modeling approach, we found that Perceived Belonging's positive influence on Actual MMORPG Usage is fully mediated by Perceived Enjoyment. In summary, this finding suggests that MMORPG developers should focus on fostering interaction between players and include more belonging-oriented aspects into their games in order to influence individuals' MMORPG Usage through the feeling of belonging.

The next section introduces the Uses and Gratifications Theory as well as the Need to Belong theory. Following this, we will present our research model and research design. We will then reveal and discuss our results before summarizing our findings, presenting their theoretical as well as practical implications, and providing an outlook on further research.

\section{Theoretical background}

\subsection{Uses and gratifications theory}

The Uses and Gratifications Theory (U\&G; Figure 1) has been used in numerous research articles 
and thus has acquired a prominent status in media research [34]. It postulates that individuals' media usage is determined by their needs and wants, which are directly linked to their ultimate goal of gratification [33].

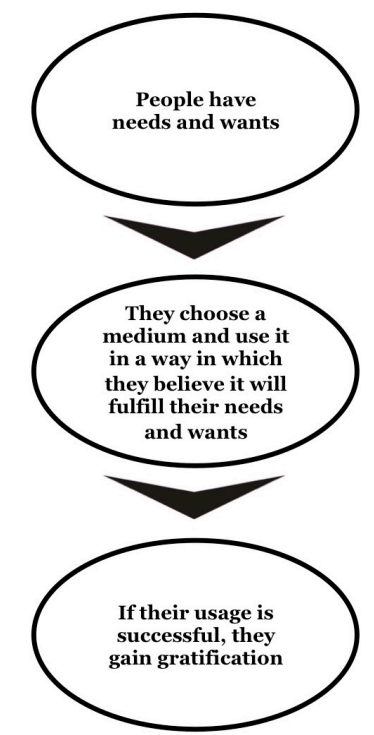

Figure 1. Uses and gratifications theory

More specifically, the U\&G assumes that people have specific needs and wants. Consequently, they are motivated to fulfill them and, hence, perform such behaviors that they believe will be able to do so. For example, imagine a curious person: the U\&G postulates that he/she will choose and use a medium if he/she believes it will gratify his/her curiosity.

Various needs and wants that can drive video game usage have been discussed in the U\&G literature. For example, it has been shown that individuals choose games that they believe gratify their specific wants such as arousal, competition, diversion, and fantasy [e.g., 36]. In the following section, we will introduce the notion of human beings' Need to Belong. Drawing from the U\&G, we will postulate later on that satisfying one's Need to Belong, in this case through Perceived Belonging, is an important driver of how often someone plays MMORPGs.

\subsection{Perceived belonging}

In evolutionary terms, belonging to a group once provided practical benefits in terms of survival and breeding [5]. For example, hunting large animals for food or defending against threats was a much easier and less dangerous task to accomplish as a group of individuals than as a single isolated individual. As a result, humans developed a Need to Belong [e.g., 5, 41], also referred to as the Belongingness hypothesis [5], Need for Love, Affection and Belongingness [27], or Relatedness Need [35].

More specifically, the Need to Belong theory postulates that every person has, to differing extents, a fundamental need to connect to others and be accepted by them. Over time, the satisfaction of this need has become more and more positively linked to hedonic well-being, represented by the presence of positive hedonic feelings such as enjoyment, happiness, and pleasure; in addition, socially isolated people suffer more from psychological problems and illnesses than non-isolated people do [5, 6, 22, 32]. Today, people still depend on the establishment and maintenance of social relationships as potential support systems [3], providing them with increased well-being, in addition to practical benefits such as support in times of need, in the form of encouragement, advice or material resources $[9,10$, 14, 41].

In summary, belonging to a group is a fundamental human need whose satisfaction provides individuals with hedonic feelings and practical benefits. As a result of this, the feeling of belonging has been identified as an important factor that motivates people's behavior. Indeed, in the media usage context, it has been shown that Perceived Belonging, i.e., the degree to which a person feels connected to and accepted by others $[5,16,27,35$, 41 , can influence the frequency of people's media usage $[15,16]$.

More specifically, Ernst et al. [16] argued that social network sites such as Facebook provide their users with functionalities that can help them feel like they belong to a larger group or help them cultivate stronger relationships with other individuals, and that the feeling of belonging is positively linked to hedonic well-being [e.g., 5, 6, 22, 32]. They empirically confirmed that Perceived Belonging is an influence factor of both the Perceived Usefulness and Perceived Enjoyment of social network sites, thus indirectly driving their usage. Similarly, Ernst and Ernst [15] argued that the Pokémon video game series allows players to feel like they belong. In this traditional role-playing game series, players have to catch animals called Pokémon and train them to battle the Pokémon of other trainers they meet along the way. Since real-life pets can be "an important source of social support", giving people a sense of belonging [28, p. 1240], and since research suggests that there might be no differences between a person's feelings towards a real pet or a virtual pet [cf. 23, 42], Ernst and Ernst [15] examined the potential influence of an individual's Perceived Belonging on how often 
he/she plays the Pokémon video games. They confirmed that Perceived Belonging, which in this case was created by companionship with the virtual pets, is a direct positive influence factor of Actual Game Use as well as an indirect influence factor of Actual Game Use through Perceived Enjoyment.

\section{Research model}

In the following section, we will present our research model (in Figure 2) and outline our corresponding hypotheses. First, we argue that video games such as MMORPGs are hedonic systems and postulate a positive influence of Perceived Enjoyment on Actual MMORPG Usage. We then argue that MMORPGs are able to satisfy individuals' Need to Belong and draw from the Uses and Gratifications Theory in order to postulate that Perceived Belonging has a positive influence on Actual MMORPG Usage, i.e., how often someone plays an MMORPG [cf. 38]. Finally, we draw from the Need to Belong theory to postulate that Perceived Belonging also has a positive influence on Perceived Enjoyment.

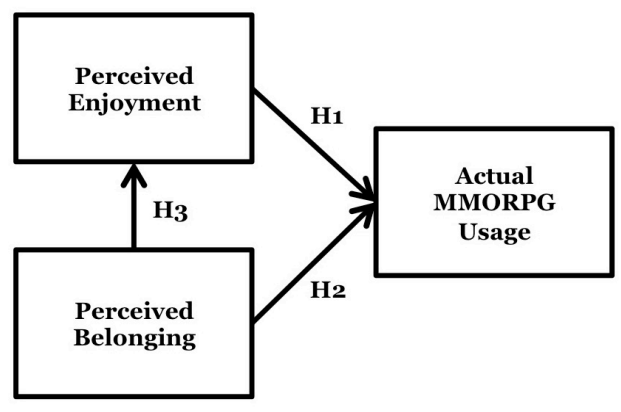

Figure 2. Research model

Video games such as MMORPGs are typical hedonic systems that "aim to provide self-fulfilling value to the user, ... [which] is a function of the degree to which the user experiences fun when using the system" [39, p. 696]. Consistently with this, numerous studies have confirmed that Perceived Enjoyment, i.e., "the extent to which the activity of using a specific system is perceived to be enjoyable in its own right, aside from any performance consequences resulting from system use" [40, p. 351], is an important driver of hedonic systems' usage [e.g., 8]. Applied to our context, these findings suggest that an individual's Perceived Enjoyment positively influences how often he/she plays MMORPGs. We hypothesize that:

Perceived Enjoyment positively influences Actual MMORPG Usage (H1).
In MMORPGs, multiple aspects can make people perceive that they belong. Indeed, in order to be able to master many of the games' quests, players usually have to strongly collaborate $[1,11]$. More specifically, players team up with other players that they meet along the way and come to appreciate. Just as in real life, liking another person is a central aspect of the feeling of belonging [cf. 18]. Before the team can actually challenge the game's harder quests, the members have to train together in numerous battles in order to become strong and capable. This means that players spend a lot of time with their group, strengthening their intergroup relationships [cf. 30]. After ultimately mastering a quest, team members have achieved the victory together, creating an even stronger bond between them [cf. 25]. These arguments are supported by the results of Cole and Griffiths [11]. Indeed, they surveyed 912 MMORPG players and found that around $3 / 4$ of their sample made good friends within the game and just under half of the sample considered their MMORPG friends to be comparable to their real-life friends. Similarly, Martoncik and Loksa [26] found that MMORPG players experience less loneliness in the virtual world than they do in the real world. In summary, we suggest that the MMORPGs are able to make people perceive that they belong, i.e., gratify their Need to Belong [e.g., 5, 41].

According to the Uses and Gratifications Theory (U\&G), individuals' media usage is determined by their needs and wants - the ultimate goal being gratification of these needs and wants [33]. More specifically, people are motivated to fulfill their needs and thus perform behaviors that they believe can help them fulfill these needs. In our context, Perceived Belonging can be described as the degree to which a person believes that the usage of an MMORPG fulfills his/her Need to Belong. Consequently, drawing from the U\&G, we believe that an individual's Perceived Belonging positively influences how often he/she plays MMORPGs. Indeed, Ernst and Ernst [15] confirmed a positive influence of Perceived Belonging on Actual Game Use in the context of the Pokémon video game series. We hypothesize that:

Perceived Belonging positively influences Actual MMORPG Usage (H2).

In addition, multiple studies have found that the feeling of belonging is positively linked to hedonic well-being, which is represented by the presence of positive hedonic feelings such as enjoyment [e.g., 5, 6, 22, 32]. In line with this, Ernst et al. [16] and Ernst and Ernst [15] confirmed a positive influence of Perceived Belonging on Perceived Enjoyment in the 
context of Social Network Sites and the Pokémon video game series, respectively. We hypothesize that:

Perceived Belonging positively influences Perceived Enjoyment (H3).

\section{Research design}

\subsection{Data collection}

To empirically evaluate our research model, we collected 71 completed German-language online questionnaires about one specific MMORPG: Guild Wars $2^{1}$. More specifically, we posted a call in a German Guild Wars 2-focused forum and, to add variance, in two general Internet forums. At the beginning of the questionnaire, we gave a short description of the game for those respondents that were not familiar with it and might not actually have played it at all, including official images and an explanation of the general gameplay [19].

51 of our respondents were male ( 72 percent) and 20 were female ( 28 percent). The average age was 28.34 years (standard deviation: 8.66). 3 respondents were unemployed (4 percent), 7 were apprentices (10 percent), 4 respondents were pupils (6 percent), 32 respondents were currently employed (45 percent), 22 were students ( 31 percent), and 3 selected "other" as a description of themselves ( 4 percent).

\subsection{Measurement}

We adapted existing and well-established reflective scales in order to measure Actual MMORPG Usage and Perceived Enjoyment. For Perceived Belonging, we adapted the Need to Belong scale [24]. For example, whereas the individual extent of people's Need to Belong is measured by items such as "I want other people to accept me", we measured Perceived Belonging by using items such as: "When I play Guild Wars 2, I feel accepted" [cf. $15,16]$.

Table 1 presents the resulting items and the corresponding sources. Actual MMORPG Usage was measured, "using 2 questions regarding the frequency with which the respondent currently ... [plays Guild Wars 2]. The first was a 7-point scale with the adjectives frequent and infrequent at the endpoints. The second was a 'check the box' format, with

${ }^{1}$ Guild Wars 2 is one of the most successful MMORPGs with more than 7 million accounts as of October 23rd 2015, which equals an increase of about 40 percent from August 2015. Players have to choose from a combination of five races and eight professions to create their avatar and team up with other players in the course of the game in order to fight dragons, other teams, etc. categories for current use of: not at all; less than once a week; about once a week; 2 or 3 times a week; 4 to 6 times a week; about once a day, more than once a day" [13, p. 991]. All other items were measured using a seven-point Likert-type scale ranging from "strongly disagree" to "strongly agree".

Table 1. Items of our measurement model

\begin{tabular}{|c|c|c|}
\hline Construct & Items (Labels) & $\begin{array}{l}\text { Source/adap- } \\
\text { ted from }\end{array}$ \\
\hline \multirow{2}{*}{$\begin{array}{l}\text { Actual } \\
\text { MMORPG } \\
\text { Usage }\end{array}$} & $\begin{array}{l}\text { On average, how often do you } \\
\text { play Guild Wars } 2 \text { ? (AU1) }\end{array}$ & \multirow{2}{*}{$\begin{array}{l}\text { Davis et al. } \\
{[13]}\end{array}$} \\
\hline & $\begin{array}{l}\text { How frequently do you play } \\
\text { Guild Wars 2? (AU2) }\end{array}$ & \\
\hline \multirow{3}{*}{$\begin{array}{l}\text { Perceived } \\
\text { Belonging }\end{array}$} & $\begin{array}{l}\text { When I play Guild Wars 2, I feel } \\
\text { accepted (PB1) }\end{array}$ & \multirow{3}{*}{$\begin{array}{l}\text { Leary et al. } \\
{[24]} \\
\text { cf. Ernst et } \\
\text { al. }[16]\end{array}$} \\
\hline & $\begin{array}{l}\text { When I play Guild Wars 2, I feel } \\
\text { like I belong (PB2) }\end{array}$ & \\
\hline & $\begin{array}{l}\text { When I play Guild Wars 2, I feel } \\
\text { connected to a community (PB3) }\end{array}$ & \\
\hline \multirow{3}{*}{$\begin{array}{l}\text { Perceived } \\
\text { Enjoyment }\end{array}$} & $\begin{array}{l}\text { Playing Guild Wars } 2 \text { is pleasant } \\
\text { (PE1) }\end{array}$ & \multirow{3}{*}{$\begin{array}{l}\text { Davis et al. } \\
{[12]}\end{array}$} \\
\hline & $\begin{array}{l}\text { I have fun playing Guild Wars } 2 \\
\text { (PE2) }\end{array}$ & \\
\hline & $\begin{array}{l}\text { I find playing Guild Wars } 2 \text { to be } \\
\text { enjoyable (PE3) }\end{array}$ & \\
\hline
\end{tabular}

\section{Results}

We used the Partial-Least-Squares approach via SmartPLS 3.2.3 [31]. With 71 datasets, we met the suggested minimum sample size threshold of "ten times the largest number of structural paths directed at a particular latent construct in the structural model" [21, p. 144]. To test for significance, we used the integrated Bootstrap routine with 5,000 samples [21].

In the following section, we will first evaluate our measurement model. Indeed, we will examine the content validity, indicator reliability, construct reliability, and discriminant validity of our constructs. Finally, we will present the results of our structural model.

\subsection{Measurement model}

Since we used common definitions and proven items from former studies, we assumed that all the constructs and measurements used were both representative and comprehensive, thus suggesting content validity [cf. 29]. Tables 2 and 3 present the correlations between constructs together with the Average Variance Extracted (AVE) and Composite Reliability (CR), and our reflective items' factor loadings, respectively: All items loaded high (.72 or more) and significant $(p<.001)$ on their parent factor and, hence, met the suggested threshold of indicator 
reliability of .70 [21]; AVE and CR were equal or higher than .74 and .89 , respectively, meeting the suggested construct reliability thresholds of $.50 / .70$ [20]. The loadings from our indicators were highest for each parent factor and the square root of the AVE of each construct was higher than each of their correlations with the other constructs, thus indicating discriminant validity $[17,21]$.

Table 2. Correlations between constructs (AVE (CR) on the diagonal)

\begin{tabular}{|l|c|c|c|}
\hline & AU & PB & PE \\
\hline Actual MMORPG Usage (AU) & $.96(.98)$ & & \\
\hline Perceived Belonging (PB) & .49 & $.74(.89)$ & \\
\hline Perceived Enjoyment (PE) & .77 & .61 & $.92(.97)$ \\
\hline
\end{tabular}

Table 3. Reflective items' loadings (t-values)

\begin{tabular}{|l|c|c|c|}
\hline & AU & PB & PE \\
\hline AU1 & $.98(102.0)$ & .44 & .72 \\
\hline AU2 & $.98(155.2)$ & .51 & .78 \\
\hline PB1 & .29 & $.72(8.7)$ & .36 \\
\hline PB2 & .43 & $.92(39.2)$ & .58 \\
\hline PB3 & .51 & $.93(60.5)$ & .59 \\
\hline PE1 & .71 & .55 & $.95(42.2)$ \\
\hline PE2 & .75 & .62 & $.97(78.8)$ \\
\hline PE3 & .76 & .57 & $.96(60.5)$ \\
\hline
\end{tabular}

\subsection{Structural model}

Figure 3 presents the path coefficients of the previously hypothesized relationships as well as the $\mathrm{R}^{2} \mathrm{~s}$ of both endogenous variable $(* * *=\mathrm{p}<.001$, $\mathrm{ns}=$ non-significant).

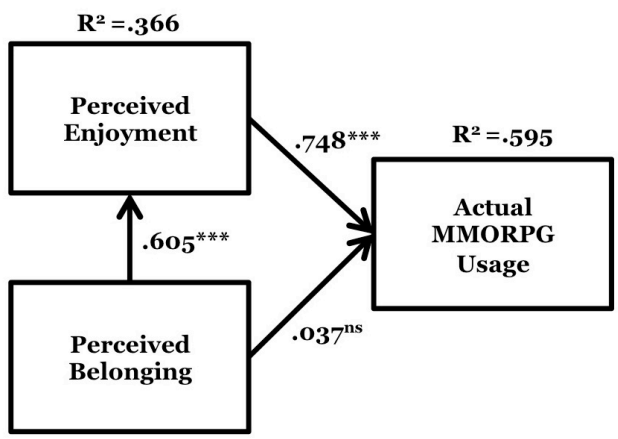

Figure 3. Findings

Perceived Enjoyment $(\beta=.748, p<.001)$ was found to have a positive influence on Actual MMORPG Usage, confirming hypothesis 1 . Also, Perceived Belonging $(\beta=.605, p<.001)$ was found to have a positive influence on Perceived Enjoyment, confirming hypothesis 3 . In contrast, hypothesis 2 was not confirmed since Perceived Belonging had no significant influence on Actual MMORPG Usage $(\beta=.037, t=.39)$. Since the direct effect of Perceived
Belonging on Actual MMORPG Usage was significant when Perceived Enjoyment was not included into the model $(\beta=.493, \mathrm{p}<.001)$, Perceived Belonging's influence on Actual MMORPG Usage is fully mediated by Perceived Enjoyment [cf. 2, 20].

Overall, the explanatory power of our structural model is good since it explains $59.5 \%$ of Actual MMORPG Usage's variance and $36.6 \%$ of Perceived Enjoyment's variance. In summary, our findings indicate that Perceived Belonging influences MMORPG usage behavior through Perceived Enjoyment.

\section{Conclusions}

In this article, we draw from the Uses and Gratifications Theory as well as the Need to Belong theory in order to study whether an individual's Perceived Belonging positively influences how often he/she plays MMORPGs. After collecting 71 German-language online questionnaires and applying a structural equation modeling approach, we found that Perceived Belonging's positive influence on Actual MMORPG Usage is fully mediated by Perceived Enjoyment.

Our study has some limitations. First, our empirical findings are based on only one specific MMORPG: Guild Wars 2. Therefore, there might be differences between this particular game and other games. Moreover, since we only surveyed Germanspeaking people, our results might not hold true for non-German speaking people. Also, our sample individuals were relatively young (mean: 28.34 years; standard deviation: 8.66). Hence, differences might be found for other age groups.

In summary, our article contributes to video game research by suggesting that Perceived Belonging is an important driver of MMORPG usage. Hence, our findings hold important practical implications. More specifically, our study suggests that MMORPG service providers should include belonging-oriented aspects into their games, in order to increase individuals' game usage through their Perceived Belonging and, hence, to secure their long-time revenue streams.

As a next step, we plan to examine drivers that could provide players with a sense of belonging such as the possibility of interacting and cooperating with other players, and Perceived Companionship, which is the degree to which a person feels that someone/something provides him/her with companionship [cf. 7, 23]. More specifically, we seek to provide MMORPG service providers with specific advice as to which game aspects provide players with a sense of belonging, and, hence, indirectly drive 
their actual MMORPG play. Additionally, we also plan to study the potential influence of Perceived Belonging on players' specific behavior in the MMORPG world such as acting prosocially, which is behavior that is "intended to benefit one or more people other than oneself" [4, p. 463].

\section{References}

[1] L. Achterbosch, R. Pierce and G. Simmons, "Massively Multiplayer Online Role-Playing Games: The Past, Present, and Future", Computers in Entertainment 5 (4), 2008.

[2] R. Baron and D. Kenny, "The ModeratorMediator Variable Distinction in Social Psychological Research: Conceptual, Strategic, and Statistical Considerations", Journal of Personality and Social Psychology 51 (6), 1986, pp. 1173-1182.

[3] M. Barrera, "Distinctions between Social Support Concepts, Measures, and Models", American Journal of Community Psychology 14 (4), 1986, pp. 413-445.

[4] C. Batson and A. Powell, Altruism and Prosocial Behavior, in I. B. Weiner, T. Millon and M. J. Lerner (eds.), Handbook of Psychology - Volume 5: Personality and Social Psychology, John Wiley \& Sons, Hoboken, NJ, 2003, pp. 463-484.

[5] R. F. Baumeister and M. R. Leary, "The Need to Belong: Desire for Interpersonal Attachements as a Fundamental Human Motivation", Psychological Bulletin 117 (3), 1995, pp. 497-529.

[6] L. F. Berkman and S. L. Syme, "Social Networks, Host Resistance, and Mortality: A Nine-Year Followup Study of Alameda County Residents", American Journal of Epidemiology 109 (2), 1978, pp. 186-204.

[7] D. Buhrmester and W. Furman, "The Development of Companionship and Intimacy", Child Development 58 (4), 1987, pp. 1101-1113.

[8] T. L. Childers, C. L. Carr, J. Peck and S. Carson, "Hedonic and Utilitarian Motivations for Online Retail Shopping Behavior", Journal of Retailing 77 (4), 2001, pp. 511-535.

[9] S. Cobb, "Social Support as a Moderator of Life Stress", Psychomatic Medicine 38 (5), 1976, pp. 300314.
[10] S. Cohen and T. A. Wills, "Stress, Social Support, and the Buffering Hypothesis", Psychological Bulletin 98 (2), 1985, pp. 310-357.

[11] H. Cole and M. D. Griffiths, "Social Interactions in Massively Multiplayer Online Role-Playing Gamers", CyberPsychology \& Behavior 10 (4), 2007, pp. 575-583.

[12] F. D. Davis, R. P. Bagozzi and P. R. Warshaw, "Extrinsic and Intrinsic Motivation to Use Computers in the Workplace", Journal of Applied Social Psychology 22 (14), 1992, pp. 1111-1132.

[13] F. D. Davis, R. P. Bagozzi and P. R. Warshaw, "User Acceptance of Computer Technology: A Comparison of Two Theoretical Models", Management Science 35 (8), 1989, pp. 982-1003.

[14] W. W. Eaton, "Life Events, Social Supports, and Psychiatric Symptoms: A Re-Analysis of the New Haven Data", Journal of Health and Social Behavior 19 (2), 1978, pp. 230-234.

[15] C.-P. H. Ernst and A. W. Ernst, "Why People Play Pokémon: The Role of Perceived Belonging", AMCIS 2015 Proceedings.

[16] C.-P. H. Ernst, J. Pfeiffer and F. Rothlauf, "The Influence of Perceived Belonging on Social Network Site Adoption", AMCIS 2013 Proceedings.

[17] C. Fornell and D. F. Larcker, "Evaluating Structural Equation Models with Unobservable Variables and Measurement Error", Journal of Marketing Research 18 (1), 1981, pp. 39-50.

[18] W. Furman, The Measurement of Friendship Perceptions: Conceptual and Methodological Issues, in W. Bukowski, A. Newcomb and W. Hartup (eds.), The Company They Keep: Friendship in Childhood and Adolescence., Cambridge University Press, New York, NY, 1998, pp. 41-65.

[19] Guild Wars 2, Guildwars2.Com, http://www.guil dwars2.com, 2016 (Accessed: 2016-09-12).

[20] J. F. Hair, W. C. Black, B. J. Babin and R. E. Anderson, Multivariate Data Analysis, Prentice Hall, Upper Saddle River, NJ, 2009.

[21] J. F. Hair, C. M. Ringle and M. Sarstedt, "PLSSEM: Indeed a Silver Bullet", Journal of Marketing Theory and Practice 19 (2), 2011, pp. 139-151. 
[22] T. A. LaVeist, R. M. Sellers, K. A. Elliot Brown and K. J. Nickerson, "Extreme Social Isolation, Use of Community-Based Senior Support Services, and Mortality among African American Elderly Women", American Journal of Community Psychology 25 (5), 1997, pp. 721-732.

[23] S. W. Lawson and T. Chesney, "The Impact of Owner Age on Companionship with Virtual Pets", ECIS 2007 Proceedings, pp. 1922-1928.

[24] M. R. Leary, K. M. Kelly, C. A. Cottrell and L. S. Schreindorfer, "Construct Validity of the Need to Belong Scale: Mapping the Nomological Network", Journal of Personality Assessment 95 (6), 2013, pp. 610-624.

[25] H. Levesque, P. Cohen and J. Nunes, "On Acting Together", AAAI 1990 Proceedings, pp. 9499.

[26] M. Martoncik and J. Loksa, "Do World of Warcraft (MMORPG) Players Experience Less Loneliness and Social Anxiety in Online World (Virtual Environment) Than in Real World (Offline)?", Computers in Human Behavior 56, 2016, pp. 127-134.

[27] A. H. Maslow, "A Theory of Human Motivation", Psychological Review 50 (4), 1943, pp. 370-396.

[28] A. R. McConnell, C. M. Brown, T. M. Shoda, L. E. Stayton and C. E. Martin, "Friends with Benefits: On the Positive Consequences of Pet Ownership", Journal of Personality and Social Psychology 101 (6), 2011, pp. 1239-1252.

[29] J.-W. Moon and Y.-G. Kim, "Extending the TAM for a World-Wide-Web Context", Information \& Management 38 (4), 2001, pp. 217-230.

[30] J. Parker and S. Asher, "Friendship and Friendship Quality in Middle Childhood: Links with Peer Group Acceptance and Feelings of Loneliness and Social Dissatisfaction", Developmental Psychology 29 (4), 1993, pp. 611-621.

[31] C. M. Ringle, S. Wende and J.-M. Becker, SmartPLS 3, http://www.smartpls.com, 2015.

[32] K. S. Rook, "The Negative Side of Social Interactions: Impact on Psychological Well-Being",
Journal of Personality and Social Psychology 46 (5), 1984, pp. 1097-1108.

[33] A. M. Rubin, The Uses-and-Gratifications Perspective of Media Effects, in J. Bryant and D. Zillmann (eds.), Media Effects: Advances in Theory and Research, Lawrence Erlbaum Associates Publishers, Mahwah, NJ, 2002, pp. 525-548.

[34] T. E. Ruggiero, "Uses and Gratifications Theory in the 21st Century", Mass Communication and Society 3 (1), 2000, pp. 3-37.

[35] K. M. Sheldon, N. Abad and C. Hinsch, "A Two-Process View of Facebook Use and Relatedness Need-Satisfaction: Disconnection Drives Use, and Connection Rewards It", Journal of Personality and Social Psychology 100 (4), 2011, pp. 766-775.

[36] J. Sherry, K. Lucas, B. Greenberg and K. Lachlan, Video Game Uses and Gratifications as Predictors of Use and Game Preference, in $\mathrm{P}$. Vorderer and J. Bryant (eds.), Playing Computer Games: Motives, Responses, and Consequences, Lawrence Erlbaum, Mahwah, NJ, 2006, pp. 213-224.

[37] Statista, Number of World of Warcraft Subscribers from 1st Quarter 2005 to 3rd Quarter 2015 (in Millions), http://www.statista.com/statistics/ 276601/number-of-world-of-warcraft-subscribers-byquarter, 2016 (Accessed: 2016-09-12).

[38] D. Straub, M. Limayem and E. KarahannaEvaristo, "Measuring System Usage: Implications for Is Theory Testing", Management Science 41 (8), 1995, pp. 1328-1342.

[39] H. Van der Heijden, "User Acceptance of Hedonic Information Systems", MIS Quarterly 28 (4), 2004, pp. 695-704.

[40] V. Venkatesh, "Determinants of Perceived Ease of Use: Integrating Control, Intrinsic Motivation, and Emotion into the Technology Acceptance Model", Information Systems Research 11 (4), 2000, pp. 342365.

[41] G. B. Watson and D. Johnson, Social Psychology; Issues and Insights, Lippincott, Philadelphia, PA, 1972.

[42] R. L. Zasloff and A. H. Kidd, "Loneliness and Pet Ownership among Single Women", Psychological Reports 75 (2), 1994, pp. 747-752. 